\title{
Theology in Times of Pandemic
}

\author{
Lluis Oviedo \\ Pontifical University Antonianum \\ Via Merulana 124 \\ 00185 Rome, Italy \\ e-mail: loviedo@antonianum.eu
}

\begin{abstract}
:
A question arises regarding theology and its functions when trying to cope with the coronavirus pandemic. Surely Christian faith - along with other religions can play a role in helping to deal with this crisis, both for individuals and collectively. Theology connects with the effort religious faith and Churches perform and provides models and ideas to highlight the Christian sense of what is happening, that is, in reference to a saving God. Four keys, rooted in the Christian tradition, are proposed that allow us to understand these difficult times in a meaningful way, that is, as revealing "signs of the times" for believers, assisting them in their struggle to cope with these challenging circumstances.

Keywords: salvation, apocalypse, conversion, paschal mystery, incarnation, religious coping, hope.
\end{abstract}

I am writing this article after two weeks of forced confinement and in the midst of one of the worst health, social and economic crises our world has experienced in recent decades, or at least wealthy Western societies, where we have not suffered such negative experiences since perhaps the tough period of the wars of the mid-20th century. This situation certainly invites reflection and analysis, although many think that it will come later, and that now there are other more urgent things to do. However, reflecting 'hot' can be a useful and necessary exercise in difficult times.

At these moments the non-rhetorical question arises about how and what can theology contribute, if it can contribute something in the middle of this struggle, if that reflective exercise from faith does not appear now rather a luxury, as something superfluous in the face of the most pressing tasks. At least, Christian faith and its practices become useful and necessary for many, for those who invoke the name of God and Mary and seek salvation, help and hope, or even inspiration to engage in risky caring activities. A first answer is linked to that perception about the helpfulness of faith in this context: if the Christian faith, and in general religious beliefs, have meaning and play important functions in these tough times, then theology is still necessary and important to guide and encourage everyone's efforts to face the crisis with which we are living. Theology is closely connected with lived experience, and takes very seriously its own contexts and challenges.

This is a critical situation that poses a test to faith and theology, that is, these times present conditions to which churches and Christian reflection must respond effectively, or else they fail in their central duties and aims. They would then, and rightly, also lose credibility. If Christian faith 
does not rise to the occasion to convey hope, comfort, and encouragement in these special moments, then it is discredited. Something similar happens with theology: if it is not capable of providing an analysis and a discourse that can interpret and give meaning to these 'signs of the times', then it becomes a sterile and useless reflection. The situation of catastrophe we are living can be read as a case of 'risk management' from a theological point of view. That perspective allows to assume an angle from which Christian reflection may become relevant and contribute, together with other strategies, to deal with the current challenges.

The theological crisis of prestige goes back a long way: it has been affected both by criticism and disdain on the part of more recognized scientific and academic discourses with greater intellectual reputation, as well by distrust in broad Catholic circles, which did not understand this intellectual effort and its practical utility. Partly it was the fault of the theologians themselves and their inability to confront the most serious problems that the faithful lived through, to offer correct diagnoses and answers or proposals to address the most critical challenges. Theology in general has lived self-absorbed and has become a self-referential exercise, with little contact with lived reality and with the problems of current people, and even more so of believers. In fact, where was the theology as the temples were emptied and confidence in the Church was vanishing? Where was it during the serious crisis of sexual abuse that has shaken many Catholic communities? We cannot fail now; I would not like to be asked where was theology and where theologians during the pandemic, when the entire population was confined, Christians could not celebrate the sacraments and many were engulfed in anxiety.

Theology has before it the challenge of becoming a much more attentive discourse to the signs of the times and to the conditions of its own context to provide analyses that could help us to understand difficult situations such as the ones we are going through, and to orient the consciences before the great uncertainty that we live. Now more than ever it is time to "give reason for our hope" (1Peter 3,15). Probably we can do better today than in former critical situations, in which a pestilence was just seen as a divine punishment. The catastrophe now lived surely opens to alternative readings and coping strategies.

In these pages I want to express the commitment of theology to society and the Church to provide a reflection inspired by Christian Revelation and the long experience of study that we have accumulated for many centuries. Indeed, this is not the first time that theology has had to deal with a great epidemic, or other calamities that periodically plague humanity and question us about our destiny and about divine action in a world seemingly left to its own and that we do not control. For this purpose, I propose four keys or models that have helped in the past, and can continue to assist making sense of this crisis we are experiencing now, and to display a range of options so that believers can choose one or more that they find most helpful and weighty or which facilitate their search for meaning. Indeed, I understand the task of theology at this time as a reflection that assists our contemporaries to project meaning in what happens from the reference to a God who saves us. Those keys are trying to establish a certain order: first, the apocalyptic, which anticipates an end through catastrophes; second, the invitation to conversion from effective signs; third, the paschal or the sacrifice that gives life beyond death; and fourth, the incarnation or accompaniment to human suffering and hopes. In what follows I will present a non-exhaustive description of these keys in their application to this specific situation.

The main inspiration for these exercise is the work of the Lutheran theologian Richard Niebuhr, Christ and Culture (1951), a book that managed to explain the plurality of choices and the unavoidable need to choose for Christians at any time, and considering a richness of models or styles on supply. We got used to his five models: from most radicals and contrasting to those looking more synthesis and convergence between our faith and our worldly circumstances.

\section{The Apocalyptic Key}

Without a doubt this is the most immediate and probably the most frequent for many centuries before other episodes of plague or great calamities. In fact, it is more than justified in the New 
Testament texts and it is easy to apply in times of great anxiety. Broadly speaking, the apocalyptic mentality understands history as a declining process, although apparently progress is registered, in reality things get worse, society and culture move further away from God; sin and corruption increases, and faith is extinguishing; only a few resist in the midst of general misunderstanding and even persecution. Everything points in this apparently calm and enjoyable environment to a profound distortion in the minds and hearts of the inhabitants of this world, who have deviated from what would be a virtuous life, in fidelity to the divine will. Given this panorama, there is no other choice but to expect a radical change that could touch everyone's heart.

The apocalyptic scenario points to a catastrophe, to the great crisis that anticipates the end of time and to a great last regeneration. Of course, ideas of punishment or divine correction arise in this context, reminding themes and episodes from the Old Testament together with a righteous mentality, because God is paying already for guilt and crime in this life, in the historical condition, or awaits the end times to do justice to his chosen ones. This key has in fact been repeatedly applied throughout history and in the midst of the greatest evils suffered by humanity and especially Christian communities. It is even too easy to understand in a key of punishment and purification the times and circumstances that we have lived through until very recently in western societies: too much frivolity, too much corruption on many levels or in many areas - including the Catholic Church - too far from God and his Church. It is not uncommon then to believe that God might grow tired of this humanity, that his anger explodes and that he corrects us with an epidemic that forces us to rethink all the certainties that we had acquired, to recognize all the errors of these years, to turn to Him.

Cognitive psychology applied to the study of religion suggests that more immediate reactions or perceptions in the religious mind following more direct or 'easy' patterns: it is about understanding God as an 'agent' behind everything that happens and still more when we cannot get a more convincing explanation, and our relationship with Him in terms of exchange, reward and punishment, as a consequence of our acts or behaviour. It can be stated that a thoughtless or fearful religious intuition feels drawn to those categories, finding it easier to think about what happens as divine punishment for the people's sins, rather than look for other explanations perhaps more complicated or subtle, more theologically elaborated. Such elaboration is the theme of the further sections of this article [1].

In any case, it is not wise to underestimate the apocalyptic perspective, which has been a source of hope and courage for many generations of Christians, and which tries to vindicate the victims and the innocent in a history full of suffering and injustice. In this view, the punishment dimension becomes less central, and Christians feel empowered in the midst of their great struggles. This was a point the German theologian J. Baptist Metz claimed in a time of great pressures and anxieties [4]. That view contributes to relativize the present, the history with everything that can be considered great or valuable: everything is reduced - except love and fidelity - when the end of time is anticipated, when the only thing that counts is the people's innermost being and the God who is anticipated at the end of the way and encourages us to draw closer to Him. He has in His hands the power to overcome evil, which can never prevail over divine grace. Therefore, it would not be advisable to discard this great vision with all that it supposes to encourage believers, and also in connection with the following key, which understands all that as a sign that calls for conversion. The apocalyptic scenario invites an anticipation of a future end of consummation, which, although it does not take place immediately, nevertheless contributes to illuminate the lives of Christians in times of strong trial, and to provide a very valuable resource: hope for those who trust God, in the midst of a despairing environment.

\section{A Sign That Invites Conversion}

This, too, is a key strongly rooted in Biblical Revelation, where times of great difficulty are perceived not so much as punishments, but as signs that invite conversion, a radical change of perspective and behaviour. This reading is often found in Old Testament Prophets, but it is also a 
key in the Gospels, which, in the face of trials and difficulties, invite conversion and following Christ. It is quite evident that the Christian tradition has repeatedly understood the great historical trials that the Church or society has suffered as invitations to review behaviours that were assumed in a too easy and sure way, to turn our eyes towards God and to change perceptions and attitudes until recently discounted.

The pandemic offers us a unique opportunity to activate an urgent reflection on the dubious drift that the western world was assuming. From a cognitive psychology point of view the issue is clear: when things go wrong, the question arises spontaneously: where have we failed? What have we done wrong to deserve this? For sure, such a mentality can be understood as naive, or again, a simple derivation of a mind that needs to identify culprits or agents of evil, also in the face of natural processes whose cause cannot be attributed immediately. Hence the abundance and popularity of conspiracy theories. The theological view must be much more subtle and not fall into a too crude or naive cognitive scheme. It does not look for culprits, and that is not the nature of the 'sign of conversion', but rather what opportunity a certain crisis or historical evil can pose to change and improve, which for us implies returning to God, accepting his will; or in other words, what is the advantage or benefit, the lesson we can draw from something so negative.

There are many reasons, when looking critically at our culture, to identify processes or attitudes that have been assumed in a thoughtless way and that invite a change of heart. There is plenty of choice, but a theological look should point out the most troubling issues. From my point of view, recent culture had entered a phase of exaggerated confidence in human capacities, supported by technical means, such as Artificial Intelligence, to overcome all our limits, fix every big problem we were finding in our way, and even to achieve immortality. I have read in recent years too many books and papers telling their great expectations based on our scientific-technical capacity to improve the world, to achieve fulfilment [5]. The dreams born during the Enlightenment were finally coming true, and our humanity was facing the true opportunity to overcome every evil, including moral evil through systems of 'moral enhancement'. All this would render full happiness much more accessible. These grandiose visions had as a clear consequence an increasing marginalization of religious faith and of Christianity in particular as a religion of salvation: we would not need salvation from supernatural instances if we could achieve it by our own means. Almost a feeling of omnipotence was taking over some intellectual sectors, and a highly successful author has even dared to speak of Homo Deus [2]. All that hubris of omnipotence, that absurd divinization, has vanished in a few days, and has given way to a sense of great fragility, to the perception that the great western civilization has feet of clay and is very vulnerable to any contingency, to the unforeseen, because we do not have control of the situation at all, no matter how much our science and our technologies, certainly necessary, advance.

Another historical episode from the beginning of the last century comes to mind that resulted in a great theological reaction and a strong social and religious change. I am referring to the reception of the Great War (1914-1918) by a group of young theologians headed by Karl Barth. It is not difficult to trace in that theological reaction themes that are now familiar to us. The young Barth composed his famous comment to the Letter to the Romans just at the end of that catastrophic war and other catastrophic pandemic (1919), which took millions of young lives ahead, as a protest manifesto against the trust inspired by the social, economic and scientific progress linked to the socalled 'liberal culture', and the complacency that most academic theology of his time showed with these tendencies, with a culture too confident in human progress. That case probably gives us signs as to how theology captured in that very dramatic situation an opportunity to rethink not only a theological model, but a whole cultural form that was too sure of itself, and that also distanced itself from God. An epochal correction was imposed, a vindication of the Christian faith in radical and ground-breaking terms: Christian faith was conceived in sharp contrast with human endeavours, as a steady correction and call to relativize every achievement.

The truth is that great difficulties and historical tests have revived the faith of so many people and that also at this time many of our contemporaries are turning their eyes towards God, praying with more intensity, trying to encourage everyone from their own faith and hope. In this 
perspective, we cannot understand the current crisis as a divine punishment, but as an opportunity to return to Him, to change our lives, giving more space to what really counts, and leaving aside false idols that have seduced us in these times with their promises of a happy life and even immortality. It is too easy to find biblical resonances in this temptation to build only relying on our own resources, but it is more appropriate - theologically speaking - to look for a different horizon, and to find a new meaning and light in what is happening. That attitude would help to correct wrong tendencies and to offer reasons of hope based on Christ and his grace.

Another experience associated with that of conversion follows from the forced situation of lockdown that most of us are living these days. This experience has given rise to austerity attitudes, to a vision of essentiality that invites us to value those things that count the most and to neglect what is secondary. Perhaps it is an important occasion to discern between the values that can provide more meaning to our lives and what is accessory: to value life, family, and friendship, above other realities so that these days we can focus in what really drives our lives, or at least to pose the big questions that really help to build a meaningful life.

\section{The Paschal Key: Death and Resurrection}

The third most relevant reason in the attempt to illuminate the events we are experiencing these days is the paschal. This key, unlike the previous two, is not as intuitive or, in other words, it is cognitively speaking - more 'expensive' or less 'easy' to perceive. The dynamic that inaugurates Christ Passover is, as some cognitive psychologists like to say, quite 'counterintuitive': death is a condition of life; self-emptying and humiliation are conditions of exaltation and glory; suffering is the way that leads to full happiness; sadness is in turn joy. These are fully Christian categories, and it is difficult to find parallels or similarities in other cultural or religious traditions; we are facing a genuine or specific point of Christian faith, which is now being tested. The closest topic in the history of religions is probably the idea of 'sacrifice': a propitiatory victim is offered to the divinity or to supernatural powerful forces to placate their rage or to substitute for the sins and wrongdoings of people. However, the Paschal sacrifice - which doubtless has been understood in that sense too demands a broader understanding, not a God to placate or a continued transgression to heal and cancel, but the opening of a different mentality and an alternative way to perceive the negative and the distressing events in life and history.

The application of the paschal principle is very familiar to Christians: the passage from death on the cross to the resurrection of Christ invites us to think that even the most negative moments of personal or collective existence can give way to a new life, beyond even from death. This principle can be understood in several ways. The eschatological key is the first: in a Christian sense, physical death gives way to a new life that anticipates the resurrection of Christ, a possibility that is open for all who follow him. Of course, this key is somewhat limited, although it is also important to remember it before the thousands of victims of the pandemic. We Christians have the right to claim that this is not the ultimate end, and that these deaths open the door to a different life, in another dimension. It would not hurt to recover in these times the strongly eschatological tone of the original Christian message, which announces life where others only see death. We have something to offer to all those who leave us abruptly and in the midst of great loneliness. They are not just figures of a sad statistic that throws us all into despair; from the paschal perspective, they are men and women called to new life in Christ, to victory over death.

Another key to reading the Passover of Christ is broader, or not reduced to the eschatological dimension: everything negative and painful that we Christians can experience refers to a horizon of transformation with the promise of a better life. Surely the human experience that comes closest to the paschal dynamics is that of self-giving love and that of sacrifice for others' sake. The idea that some expressions of love require self-denial, or the surrender beyond one's own interests to get access to more exalting and full states is not new or strange for those who discover love beyond its superficial forms or just the erotic version. However, the Paschal dynamic contains within it a promise that goes beyond the experiences of self-sacrificing love, or sacrifice for other 
people, or at least gives them full meaning. In fact, Easter offers a horizon or a guarantee that allows us to go through any form of negativity and suffering in the hope that they will change into joy and fulfilment; Or, in other words, it offers to those who in these difficult times sacrifice themselves for others the promise that their love will not be in vain. The profound idea of the Passover of Christ is that all the good that we have been able to do will remain forever, it does not fade away, it does not die, but it is projected to eternity, as had happen with thee good Christ did perform during his ministry by us. In the dead and risen Christ we have the certainty that our love, tested in the crosses of each day, all the good done, will be forever and will never die.

\section{Faith as Incarnation and Accompaniment}

The fourth theological key that I propose in order to provide a meaning to these times of trial is the one that invites us to share and assume both the pains and the sometimes heroic gestures of dedication that we observe, as a manifestation of God's grace, as the presence of his Spirit who lives among us. It is a more reflective key, which is born from a view capable of perceiving the gift of God and his mysterious presence in the events that humanity lives, both positive and negative. This perception is placed at the other extreme regarding the apocalyptic mentality: where the apocalyptic sees degeneration and decay, the incarnate person observes the work of God, his love present in many ways; where the first sees above all experiences of sin, the second perceives expressions of grace; where the first sees negativity that invites a catastrophic end to purification, the second sees much love and dedication, much hope. It is close to the mystical experiences in many religious traditions, a mysticism able to discern the divine presence in its mysterious forms, but close too to human experiences of empathy and compassion, to a deep rooted tradition able to connect the best expressions of human love and self-giving to the divine.

The theological exercise in this case focuses on everything that reveals the best of humanity in the midst of its wounds, because it assumes a vision from within that human condition, which also reveals its greatness. This perspective takes advantage of and strongly applies the initial declaration of the dogmatic constitution of Vatican II, Gaudium et spes:

The joys and the hopes, the griefs and the anxieties of the men of this age, especially those who are poor or in any way afflicted, these are the joys and hopes, the griefs and anxieties of the followers of Christ. Indeed, nothing genuinely human fails to raise an echo in their hearts... That is why this community realizes that it is truly linked with mankind and its history by the deepest of bonds (GS 1).

For this reason, the Church can read the situation that humanity lives in these times, with its lights and shadows, from within it, and not from the outside, as those who judge from above. The Christian faith discerns in what is happening the signs of life that are reflected in all the efforts made at different levels of a society that feels threatened and insecure, even scared. In this situation, faith learns to be close and share, to encourage everyone and to announce hope.

Several theologians have insisted in recent years that the believing mission to recognize the providential action of God is not identified in the extraordinary, the supernatural or in the limits of natural processes, but in the very dynamics of creation and in the efforts of science, in the best of humanity that walks towards overcoming evil [3], [7]. This is a unique opportunity to discern the presence of God both in those who suffer most and in those who love and serve others.

\section{Some Concluding Remarks}

These times are testing many realities, many proposals and we are not sure how we will live, how we will feel after all this will be over. The truth is that an important result of this state of affairs is that it has forced us to rethink the Christian faith as a 'salvation religion' and not only as a spiritual expression, almost as something close to the aesthetic experience. In this sense, the Christian faith 
recovers its genuine character, provided that it really knows how to help people of our time to face and overcome these difficulties. In this regard, it should be remembered that religious faith is best seen as a 'coping system', as 'religious coping', that is, a series of resources - beliefs, rites, prayers - that help those who apply them to address difficult or critical moments. A focused research we have conducted in recent years [6] indicates that such a faith-based coping strategy works best when combined with other secular strategies, such as therapeutic help, friendship, or knowledge and study. This data again points to the Christian faith being called to walk alongside other positive expressions, not apart or not in competition. This is something that can also be deduced from the current situation, in which we all are called to offer the best to face our great challenges.

Christian faith becomes in the current context a way to look at an experience of perceived risk and generalized catastrophe, but a plural one; or better: it offers a set of cognitive resources to cope with that situation. Its 'management' cannot assume the form of other 'rational strategies', which look for effectiveness and results, since Christians are used to apply categories like grace, gift, and eternity that defuse sheer pragmatic criteria. However, the coping strategies it builds and offers before catastrophic processes are very helpful for many, and should be taken into account by those who hold public responsibilities. The working of Christian faith can hardly be assessed, except in the innermost experiences of people, which, by their own conditions, can hardly become subject to any management. This condition is the one that renders faith and grace more mysteriously effective and can bear lasting and deep consequences.

My colleague and friend Konrad Szocik has pointed out - after reading a former version of this paper - that the current situation reveals intrinsic fragilities and vulnerability in human condition, something that will never be overcome, despite the false promises of transhumanists and optimist technologists. This perception renders theology an unavoidable reflection. After all, "Theology may be the last conceptual system which reminds us of that fact [our fragility] independently on human hope for science" (Szocik). The question is to what extent such a reminder becomes useful. Possibly only at the condition that theology provides at the same time a hint of hope and resources to cope.

And one last note. Many of us miss in the public appearances of our politicians and authorities, especially when they make the most dramatic and solemn announcements, a necessary conclusion: "May God help us." It would be a sign of real and concrete post-secularization, a way of giving hope to all over the divisions.

\section{References}

1. Barrett, J. L. Why would Anyone Believe in God? Lanham, MD: Altamira Press, 2004.

2. Harari, Y. N. Homo Deus: A Brief History of Tomorrow, New York: Harper, 2017

3. Knight, Ch. C. The God of Nature, Incarnation and Contemporary Science, Minneapolis: Fortress Press, 2007.

4. Metz, J. B. Glaube in Geschichte und Gesellschaft: Studien zu einer praktischen Fundamentaltheologie, Mainz: Mattias Grünewald Verlag, 1977.

5. Tegmark, M. Life 3.0: Being Human in the Times of Artificial Intelligence, London: Penguin, 2017

6. Torralba, J., and Ll. Oviedo. Religious coping in adolescents: New evidence and relevance (under submission).

7. Yong, A. Renewing Christian Theology: Systematics for a Global Christianity, Waco, TX: Baylor University Press, 2014. 